\title{
ICT in Teaching Latin and Foreign Languages at the Medical University
}

\author{
Olga Yurievna Olshvang \\ Ural State Medical University \\ Ural State Federal University \\ Yekaterinburg, Russia \\ Olga020782@mail.ru
}

\author{
Olga Georgievna Olekhnovich \\ Ural State Medical University \\ Yekaterinburg, Russia
}

\author{
Irina Sergeevna Arkhipova \\ Ural State Medical University \\ Yekaterinburg, Russia
}

\begin{abstract}
This article presents electronic learning resources developed by teachers for teaching students foreign and Latin languages at the medical university. The effect of the introduction of these electronic resources in the educational process on the performance and motivation of students is described. The described electronic learning resources are divided into four groups: electronic textbooks, video lectures, electronic dictionary and simulators. These resources were created using ready-made tools for creating online courses (Adobe Presenter, Quizlet platform) and with the help of a programmer to develop our own online and offline applications (vocabulary and grammar simulator, Latin-Russian and Russian-Latin dictionary "Tempus"). The use of textbooks on electronic and paper media in the framework of the courses "Foreign Language" and "Latin Language" is compared. The role of electronic learning resources in the organization of students' independent work is noted. This paper describes the difficulties that teachers face in developing electronic learning resources.
\end{abstract}

Keywords - electronic learning resource; Latin language; foreign language, electronic dictionary, English for specific purposes

\section{INTRODUCTION}

Currently, information and communication technologies (ICTs) provide new forms of organization of learning / teaching, in particular, foreign languages. Thanks to ICT and multimedia resources, new tools used in teaching and learning are being developed. This article examines the attitude of students to ICT in the courses "Foreign language" (Foreign language for specific purposes) and "Latin language" at the medical university and the impact of the introduction of electronic learning resources on students' achievements and academic performance. In modern science, there are different approaches to the definition of English for specific purposes (ESP). A number of studies distinguish a language for specific purposes (LSP) [1, 2]. In French studies, this approach is called Français sur Objectifs Spécifiques. A foreign language for specific purposes, as defined by French researchers J.-M. Mangiante and C. Parpette, refers to the development of a syllabus for a specific audience with clearly defined needs [3].
Typically, such courses are limited in time, which forces the teacher who develops the syllabus to prioritize the choice of content and skills being developed. Unlike Language for Specific Purposes, the syllabus for the Professional Foreign Language (Français de spécialité) is not aimed at a specific audience of students, it is more general, designed for students of the whole field of study (English for Medicine, English for Economics, English for Law, etc.). When teaching a professional foreign language, the teacher does not need to identify the needs of his/her audience in order to adapt the syllabus each time, since this course involves the coverage of all communicative situations encountered in this field of study. As J.-M. Mangiante pointed out, "the goal is not the audience, but the professional language, or rather, a set of specialized discourses in this field" [4]. V. Vaiciuniene opposes ESP to General English, which aims to study grammar, vocabulary and to develop communication skills [5]. M.E. Butler-Pascoe proposes to consider ESP as a hybrid approach that combines teaching both language and field specific content [6]. In the context of this study, following $M$. Zakhir [7], we will consider LSP as a course aimed at improving the communicative skills of students and knowledge of a foreign / Latin language in the field of study without going deeper into the theoretical aspects of language learning (language history, lexicology, etc.). Due to the need to include content related to the field of study, experts in the field of anatomy, pharmacology, epidemiology and therapy were involved as experts, co-authors and reviewers of ESP and Latin language courses.

Over the past few decades, many studies devoted to the peculiarities of teaching foreign languages $[8,9]$ and LSP $[10$, 11], in particular, consider the role of ICT in the educational process. On the one hand, the introduction of ICT implies appropriate technical equipment of classrooms, devices for students, the development of the necessary technical skills (for both students and teachers), and on the other hand, it requires the reform of the educational process itself both in classroom teaching and student learning. N.Y. Asabere and S.E. Enguah defined ICT as the tools, facilities, processes, and equipment that provide the required environment with the physical 
infrastructure and the services for the generation, transmission, processing, storing and disseminating of information in all forms including voice, text, data, graphics and video [12]. Computer, internet, smart boards, cell phones, video games, music players etc. are used in the target language learning process to raise students' motivation and language awareness [13]. Interactivity and flexibility are another advantage of using ICT in the educational process [14]. ICTs provide access to an array of authentic materials, allow to vary the form of organization of classes, and stimulate practicing language. Students have a choice of learning style, which creates a stress-free learning environment [15]. In addition, ICTs allow to modify teaching materials to adapt them to the needs of students, allow to carry out a comprehensive assessment of students' receptive and productive skills and to identify problems, to increase the level of organization and the quality of independent learning [16].

At the same time, the use of ICT requires a sufficiently high level of technical and methodological training of the teacher (to select tools and technologies that are appropriate for the student's learning style, purpose and content of the lesson) and students' technical skills [17]. The introduction of ICT requires large financial investments in the equipment of classrooms and the availability of a technical specialist to service and support software and hardware. Thus, ICTs in teaching LSP and Latin language have not only advantages, but also limitations.

\section{MATERIALS AND METHODS}

In all Russian universities, the subject "Foreign Language" is compulsory and is taught at the first year or the first and second years; the study of the subject "Foreign Language" is designed for 108-360 hours, including classroom studies and student's independent work (depending on the profile). The subject "Latin Language" is compulsory in the first year of medical and pharmaceutical universities and is designed for 72-144 hours, including classroom studies and student's independent work (depending on the profile).

This empirical study presents electronic learning resources developed by teachers of the Department of Foreign Languages and used in the educational process to teach students Latin and foreign languages at the medical university. The role of these resources in increasing the motivation of students is considered. This study also uses the observations and results of a survey of students' opinions on the role of electronic learning resources in the educational process.

Electronic learning resources in Latin and foreign languages developed by teachers can be divided into 4 groups.

Electronic textbooks. Traditional textbooks, which were previously published on paper, but are now available on the elearning platform of the university, contain theoretical material (grammar rules), assignments, basic vocabulary, exercises for independent work which are checked automatically. This type of electronic learning resources makes it possible to provide all students with textbooks at the lowest cost for the university, students can access the textbook anywhere, they only need a mobile device or PC connected to the Internet.
Video lectures. In accordance with the curriculum, video lectures for each Latin lesson were prepared using Adobe Presenter software and were posted on the e-learning platform of the university. The advantage of such lectures in comparison with posting a Power Point presentation is that the student can not only listen to the theoretical material studied in the lesson, but also perform a test to check the understanding of the topic studied with automatic check. When preparing lectures with Adobe Presenter software, it is possible to display a teacher's video (talking head) in parallel with the presentation in a separate window. The table of contents of the lecture is displayed to the right of the presentation, which provides convenient navigation through the lecture and allows to return to the slide of interest.

Latin-Russian and Russian-Latin electronic dictionary "Tempus" (web application). Although the latest versions of the popular electronic dictionaries Abbyy Lingvo and Multitran have Latin-Russian and Russian-Latin dictionary, it does not contain medical terms. In connection with the demand from students, teachers of Latin language developed an electronic Latin-Russian and Russian-Latin dictionary "Tempus". The uniqueness of this resource is that it presents pharmaceutical and medical terminology. In the electronic Latin-Russian dictionary entry, the word is given in the root form (nominative case for nouns, adjectives, participles, infinitive form for the verb), other forms (genitive case for nouns, feminine and neuter forms for adjectives and participles), constant grammatical characteristics (gender category for nouns, conjugation type for verbs), meaning in Russian and collocations, examples of use in Latin with translation (this section also provides cultural information, and popular expressions containing this lexical unit with Russian translation), acronyms and abbreviations (abbreviations are widely used in anatomic, clinical and pharmaceutical terminology). For prepositions, the case (cases) with which they are combined is (are) indicated. All grammatical forms (the declination / conjugation paradigm) are also embedded in the dictionary entry of each word. Thus, the electronic dictionary entry was significantly expanded in comparison with the paper version. Since the search is carried out in all fields of the dictionary entry, the search word will be displayed in the search results even when students type a noun or an adjective in the indirect case or a finite verb. In addition, the search can be carried out by a single morpheme, thus, it is possible to search by the Greek root, for which there is no separate dictionary entry. The direction of the translation is determined automatically in accordance with the input language, so there is no need to switch between the Latin-Russian and Russian-Latin dictionary. The electronic dictionary allows to make timely additions and updates with the release of new editions of textbooks, changes in regulatory documents (publication of a new Pharmacopoeia, etc.), the creation of new drugs, as it exists as a web application. In addition, this form does not require the development of different versions of the dictionary for each operating system and for mobile devices.

Simulators. The Latin phonetic simulator provides a detailed analysis of the rules for reading letters and letter combinations in Latin in different positions with examples, each of which is accompanied by an audio file. The 
vocabulary and grammar simulator in Latin language (available online and in the form of a mobile application) contains vocabulary and grammar material on all topics of the course. When choosing a topic, 10 pairs of words are displayed on the screen which shall be matched. The next time this topic is addressed, the student will be given with those pairs of words where a mistake was made (thus, intellectual selection of pairs of words is carried out). The simulator on Quizlet platform allows to master vocabulary on each topic in a play-based manner, as well as to simulate a dictation. Courses for each faculty were created on Quizlet platform at the initiative of students and with their immediate participation. The module contains all the words included in the basic vocabulary for each topic. Students can choose the mode of learning vocabulary in the form of cards with words in Latin and Russian (at the same time there is an opportunity to add an illustration to each word), listen to the pronunciation of each word, write a dictation. The control mode is also available in the form of a test and a matching game and "gravity", when limited time is given to write a translation of the word that appears on the screen. At the university's elearning platform there are tests on each topic of the course, as well as final tests with a random selection of multiple choice questions from all the topics of the course in foreign and Latin languages which can also be used as a simulator. Latin tests contain questions to check knowledge of vocabulary and grammar; foreign language tests include questions on understanding a scientific text in the field of study along with questions to check knowledge of vocabulary and grammar.

\section{RESULTS AND DISCUSSION}

Most of the above-mentioned developed resources are intended for Latin lessons. This is due to the fact that a large number of authentic high-quality ESP textbooks (English for Medicine, in particular) have already been published (Oxford English for Careers: Nursing 1; English in Medicine: a Course in Communication Skills; English for the Pharmaceutical Industry etc.), which include audio, supplementary materials, links to external multimedia resources. A great deal of audio and video materials are available online for free that can be used in class and recommended to students as part of independent work. This course is also provided with paper and electronic LSP and general dictionaries. Most of authentic LSP textbooks are more suitable for students majoring in "General Medicine" and "Pediatrics", therefore, teachers have developed electronic LSP textbooks for students majoring in "Preventive Medicine", "Dentistry", and "Clinical Psychology". Thus, LSP teachers need to choose from readymade authentic multimedia materials those that will correspond to the purpose and content of the lesson, as well as the level of students' foreign language proficiency. Using authentic teaching and multimedia materials, students show interest in the subject and have higher motivation.

If in the classroom students were given printed texts and exercises which were available in electronic textbooks, students often preferred an electronic version for skimming and scanning the text in a foreign language. This is due to the convenience of navigating in the electronic document, using the search function throughout the document.
The use of electronic resources at the lessons of foreign languages makes it possible to organize the independent work of students more rationally, to implement a level-based approach. Since the university is not linguistic, students with different levels of language proficiency (from A1 to B2) may be enrolled in the same group and it is not always possible to form groups taking into account the level of students' foreign language proficiency. In this case, the use of electronic learning resources allows to vary the tasks for students, rather than focusing on the average level of the group (in the latter case, there is a risk of losing interest and motivation of students who speak a foreign language at the elementary level (A1), because they do not understand what is happening in the classroom and they may fail the final test / exam at the end of the course, and, on the other hand, there is a risk of losing the interest and motivation of advanced students, because the training materials will seem too easy to them).

While students do not need special training and technical skills when using audio and video materials in the classroom or during independent work, some students need additional explanations when working with the dictionary. A dictionary is an important element in language learning. The choice of the dictionary, as well as the correct strategy for its use, can have a significant impact on the success of learning process. In our opinion, it is advisable to train students to competently use paper and electronic dictionaries, drawing their attention to the existence of various types of dictionaries, grammatical information contained in the dictionary entry and dictionary annexes (or in the electronic dictionary entry), the possibility to check the pronunciation of the word.

Electronic dictionaries can be represented by web applications (available online, do not require the installation of special software, particular specifications of the operating system) and stand-alone applications that are installed on a PC or mobile device. The advantage of electronic dictionaries is undoubtedly the ability to update them, add new terms, this can be done in real time. This function is available in stand-alone applications (for example, Lingvo) and in web applications (for example, Multitran, where any registered user can add a dictionary entry or a meaning to the existing dictionary entry by filling out the form). Among the electronic dictionaries available online, one can also distinguish a group of contextual dictionaries (https://context.reverso.net; www.linguee.ru), where the search is performed through an array of translated official documents, websites with synchronized versions in different languages etc.

When working with an electronic dictionary (for example, Lingvo application), students can simultaneously look up a word in the general dictionary and LSP dictionaries, which is especially useful when working with a scientific text (when working with medical texts, it makes sense to look up the work not only in the medical dictionary, but in the biological and chemical dictionaries, which increases the likelihood of finding an equivalent). When using a dictionary, students need to understand that it is impossible to select automatically the first meaning given in the dictionary entry. It makes sense to pay attention to the examples given in the dictionary entry, where students can find the idiomatic expressions of interest, to take into account the collocations. If, when working with a paper 
dictionary, the search for an idiomatic expression may require reading the entire dictionary entry, in the electronic dictionary students can search for the whole collocation (it can exist as a separate dictionary entry in the electronic dictionary or found in the text of the dictionary entry, since electronic dictionaries often search across all fields, not just the head word).

Technologies allow students not only to improve the quality of learning process but also to "automate" the process of completing tasks (for example, machine translation systems), which does not contribute to improving the quality of training. So it is important to show the difference between electronic dictionaries and machine translation systems and encourage the learners to use proper tools when learning languages. Students who speak a foreign language at the elementary level often choose a bilingual general dictionary from the proposed paper dictionaries, and as for the electronic dictionaries they prefer the Google service (when the use of machine translation of the text is prohibited, they use word-by-word translation). In the word-by-word translation, this service provides a set of synonyms, a number of equivalents arranged by frequency of use, examples of use and the meaning of the lexical unit of interest, but students most often use only the first meaning given in the translation window.

When working with text, more advanced students in the foreign language (B1+ and above) are able to choose a dictionary that suits their needs. In addition, such students already have necessary skills how to work with a dictionary, using context and word-building elements, they can determine the meaning of a word without looking up at the dictionary. In the case of students who speak a foreign language at the level of $\mathrm{B} 1+$ and above, it is worth encouraging the use of monolingual, explanatory dictionaries, since when reading a dictionary entry the student is forced to think in a foreign language and draw conclusions. This skill is especially useful when a term is found in the text for which there is no equivalent in a bilingual dictionary.

Most of the electronic learning resources in Latin language are used by students as part of independent work. To work in the classroom, students were offered paper versions of textbooks. In individual work, identical textbooks in electronic format were used on the university's e-learning platform.

The vast majority of students praised the introduction of a phonetic simulator for independent work. Its use allowed to significantly improve the results of the phonetic test (97\% pass at the first attempt).

At the initial stage of working with vocabulary, a vocabulary and grammar simulator developed by teachers of our department and a Quizlet simulator, as a rule, are also popular among students, which is explained by the userfriendly interface, the game element in the presentation of the material, the novelty compared to the traditional technique. Although the Quizlet platform involves an interactive mode for use during traditional classes, in our opinion, it is advisable to use this tool in learning Latin as part of independent work. The possibility to enter the correct answer manually allows to avoid the disadvantages of traditional online tests, where a choice from suggested options is offered. The possibility to voice each term allows to use the platform as a phonetic simulator when learning how to read (however, the main purpose of using this resource is to memorize and to revise vocabulary). When using this web application in game mode, during which it is necessary to match the word and its translation, an element of competition appears, since each player is given a limited time to complete the task, and the result is compared with other users.

Latin and foreign language tests for each topic, posted on the university's e-learning platform, are used as mock tests. Apparently, a less attractive interface compared to the abovementioned resources explains a much less interest in these tests. Current vocabulary tests are conducted in the form of bilateral dictations. At the midterm tests, students are given a question/answer test since the multiple choice test or matching items do not allow to fully check the receptive and productive communicative skills (an interview on the topic studied is also conducted in the foreign language)

If a deep and detailed study of the topic is necessary (preparation for dictations in Latin, midterm tests), the majority of students (87.5\%) also used paper media (paper versions of textbooks, printouts of basic vocabulary). At the same time, better academic performance was observed in those students who used only paper textbooks or paper textbooks in combination with electronic resources. The results of our study are consistent with the results of a number of ESP researchers [18, 19, 20, 21].

Latin video lectures were originally developed to test the "flipped classroom" technique, but in most cases we encountered poor compliance in students (due to home assignment in other subjects, no sanctions for failure to view the lecture before the lesson). At the same time, according to the statistics of the e-learning platform, the number of lecture views increased significantly before the current and midterm tests. As the students themselves noted, video lectures were useful not only when revising the topics studied before the test, but also when missing classes.

At the end of the course "Latin Language" and "Foreign Language", a survey of students' opinions was conducted on Google forms in order to receive feedback. To the question "What would you like to improve in organizing the course?" many students $(89.7 \%)$ reported their preference for using paper textbooks for learning vocabulary. At the same time, respondents praised the diversity of Latin electronic learning resources.

\section{CONCLUSION}

The introduction of ICT significantly enhances students' motivation in mastering the subjects "Foreign Language" and "Latin Language", provides better training for students in practical classes, current and midterm tests and exams. Thanks to the use of electronic learning resources in the educational process, students' performance has significantly improved (including due to better organization of students' independent work, easy access to teaching materials). Thus, in our opinion, the introduction of ICT and the use of electronic learning resources, in particular, play an important role in the educational process. It helps to increase students' motivation, but information sources on paper should not be completely 
excluded. When using one or another resource and information media, it is important to consider the tasks that students face.

When using electronic learning resources for skimming or scanning a text (in the LSP classes) or as a reference (online and offline electronic dictionaries), as well as multimedia resources (video lectures, simulators), students noted their benefit and convenience due to their presentation and interactivity. However, if necessary, the students preferred paper media to prepare for a bilateral dictation (for basic vocabulary). These results can be explained as follows. Paperbased textual information is more readable, especially when a linear presentation of the information is intended. Nonlinearity of narration on paper can be organized through comments and footnotes, but it will not be as convenient and effective as in the virtual environment. Researchers also note the psychological comfort and convenience of paper media at the level of simple manipulation $[22,23,24,25,26]$. The virtual environment provides the opportunity to create active sections of text, hyperlinks, that allow to go to other parts of the document or new documents, to activate pop-up comments, which makes it more convenient for presenting reference information and dictionaries. Better presentation in the virtual environment is achieved due to the multimedia component (animation, sound, images, video), which also explains the reason for the attractiveness of video lectures and a phonetic simulator and vocabulary and grammar simulators.

When creating electronic learning resources, we encountered the following limitations and technical difficulties. To develop and support our own applications (vocabulary and grammar simulator, Tempus Latin-Russian and Russian-Latin dictionary), we had to involve a programmer. To create video lectures, commercial software Adobe Presenter was used. Undoubtedly, the sound track can be attached to slides of the presentation using standard Power Point tools or standard Windows tools (for example, Movie Maker). But the resulting product will have limited functionality (no tests with automatic check after the lecture, no table of contents for the lecture which facilitates navigation within the lecture, no talking head option in parallel with the presentation of the slides).

\section{References}

[1] L. Anthony, "English for Specific Purposes: What does it mean? Why is it different?" On-CUE, vol. 5/3, pp. 9-10, 1997.

[2] M. Zakhir, "The Role of ICT in Teaching ESP Classes," International Arab Journal of English for Specific Purposes (IAJESP), vol. 1(1), pp 21-36, 2018

[3] J.-M. Mangiante and C. Parpette, Le français sur objectif spécifique, de l'analyse des besoins à l'élaboration d'un cours. Nouvelle collection f. Hachette FLE. 2004

[4] J.-M. Mangiante, Des référentiels de compétences en français à visée professionnelle: Des outils pour concevoir des formations pour publics spécifiques. Le français de spécialité: enjeux culturels et linguistiques. Editions Ecole Polytechnique, 2008, pp. 83-104.

[5] V. Vaiciuniene and D. Uzpaliene, "Authentic resources in technologybased ESP learning”, Studies about languages, vol. 17, pp. 94-98, 2010
[6] M.E. Butler-Pascoe, "English for specific purposes (ESP), innovation, and technology", English education and ESP, vol. 3(3), pp. 1-15, 2009.

[7] M. Zakhir, "The Role of ICT in Teaching ESP Classes", International Arab Journal of English for Specific Purposes (IAJESP), vol. 1(1), pp 21-36, 2018.

[8] C. White, "Autonomy and strategy use in distance foreign language learning: Research findings," International Journal of Educational Technology and Applied Linguistics, vol. 23(2), pp. 207-221, 1995.

[9] Y. Zhong, "A study of Autonomy English Learning on the Internet", English Language Teaching, vol. 1(2), pp. 147-150, 2008.

[10] J. Schoonenboom and R. B. Johnson, "How to construct a mixed methods research design", Kolner Zeitschrift fur Soziologie und Sozialpsychologie, vol. 69(Suppl 2), pp. 107-131, 2017.

[11] M. Spratt, G. Humphreys, and V. Chan, "Autonomy and motivation: Which comes first?" Language Teaching Research, vol. 6(3), pp. 245266, 2002.

[12] N.Y. Asabere and S.E. Enguah, "Integration of expert systems in mobile learning. International", Journal of Information and Communication Technology Research, vol. 2 (1), pp. 55-61, 2012.

[13] M. Altun, "The integration of technology into foreign language teaching", International Journal on New Trends in Education and Their Implications, vol. 6(1), pp. 22-27, 2015.

[14] D. Cakici, "The use of ICT in teaching English as a foreign language", Participatory Educational Research (PER), vol. 4, pp. 73-77, 2016.

[15] N.S. Jayanthi and R.V. Kumar, "Use of ICT in English language teaching and learning", Journal of English language and literature, vol. 3(2), pp. 34-38, 2016.

[16] A. Padurean and M. Margan, "Foreign language teaching via ICT", Revista de Informatica Sociala, vol. 3(12), pp. 97-101, 2009.

[17] I. Alizadeh and F. Ebrahimi, "Investigating medical students' readiness for technology-mediated autonomous learning situations in ESP programs", Education and Innovation Technologies, vol. 24(6), pp. 3289-3309, 2019

[18] K. Karabayeva, "Thinking Globally: ICT Teaching Perspective", Procedia - Social and Behavioral Sciences, vol. 197, pp. 466-475, February 2015 [7th Conf. World Conference of Educational Sciences, $p$. 514, 2015].

[19] I. Simonova, "The ICT-supported process of ESP instruction Comparative study", Procedia - Social and Behavioral Sciences, vol 143, pp. 407-413, August 2014 [Conf. on Educational Research, p. 495 , 2014].

[20] E. Sokolova, V. Rostovtseva and M. Wasilewski, "The Advantages of the Network-based Electronic Teaching Package by the Implementation of English for Specific Purposes Course", Procedia - Social and Behavioral Sciences, vol. 206, pp. 193-198, November 2015 [15th Conf. Linguistic and Cultural Studies: Traditions and Innovation, p. 206, 2015].

[21] M. C. Wittrock, "Generative learning processes of the brain", Educational Psychologist, vol. 27(4), pp. 531-541, 1992

[22] D. V. Chulkov and J. VanAlstine, "College student choice among electronic and printed textbook options", Journal of Education for Business, vol. 88(4), pp. 216-222, 2013.

[23] D. B. Daniel and W. D. Woody, "E-textbooks at what cost? Performance and use of electronic v. print texts", Computers \& Education, vol. 62, pp. 18-23, 2013.

[24] A. Feldstein, M. Martin, A. Hudson, K. Warren, J. Hilton, and D. Wiley, "Open textbooks and increased student access and outcomes", European Journal of Open, Distance and E-Learning, vol. 2, pp. 1-9, 2012.

[25] A. Mangen, B. R. Walgermo, and K. Brønnick, "Reading linear texts on paper versus computer screen: Effects on reading comprehension", International Journal of Educational Research, vol. 58, pp. 61-68, 2013.

[26] M. Millar and T. Schrier, "Digital or printed textbooks: Which do students prefer and why?" Journal of Teaching in Travel \& Tourism vol. 15(2), pp. 166-185, 2015 . 